The question may be asked, Could the remarkable qualities of this summer (so hot and $d r y$ ) be foreseen in any measure I consider there was reason to expect a very small rainfali (at Greenwich); and I would submit the enclosed rough dot diagram in support of this view.
$4042444648505254365860.626466 \quad 68$

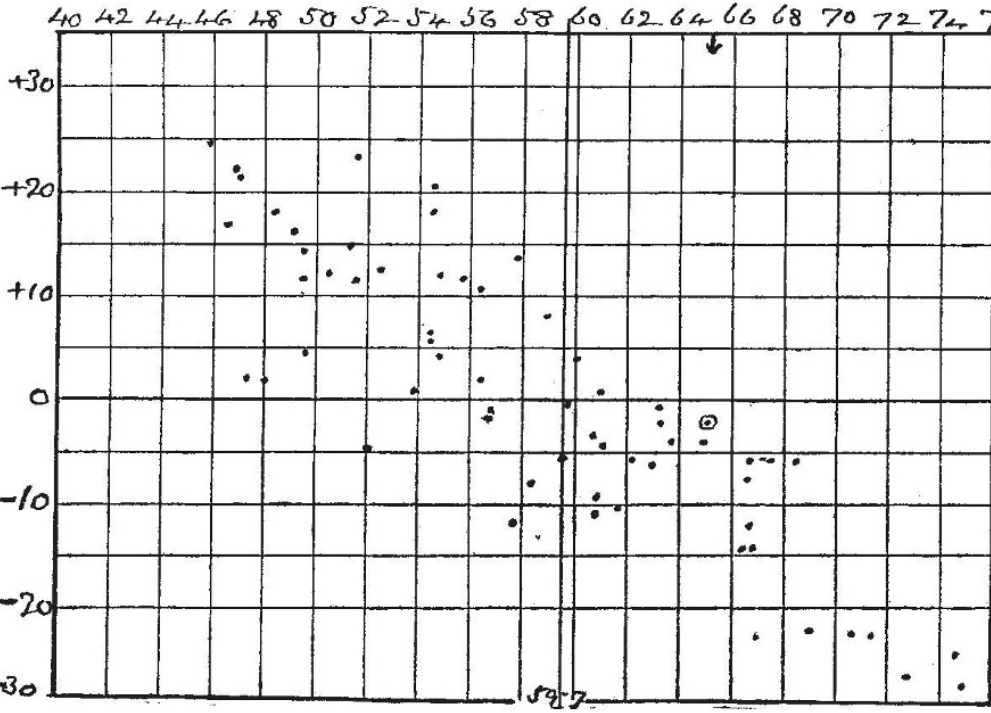

Rainfall compartson of Greenwich summer.

It is got thus: the rainfall of spring plus summer (March-August) in each year, I84I-I910, is noted, and these values are added in groups of five (1841-5, 1842-6, \&c.). Then each sum is compared, by the dot method, with the difference between it and the fifth after, a plus value meaning that the later sum is the higher, while a minus value means it is lower. (Each dot signifies one sum by the horizontal scale, and the difference by the vertical.)

Before this summer we had got to comparing the sum for 1903 (i.e. the group 1901 to 1905), which is 68.4 inches, with the difference between it and the sum for 1908 (i.e. 1906-10), which is 6 inches $(68 \cdot 4-62 \cdot 4)$. Next we have the sum for 1904, which is 65.3 inches, and the value for 1909 has to be ascertained (i.e. the group 1907-1 I).

Find 65.3 in the horizontal scale (see arrowhead), and consider where the new dot is likely to go. (The encircled dot shows its actual position.) It will be seen that, wherever the sums have exceeded (say) 62 inches, the fifth sum after has been a lower value hitherto. Let us lessen the sum 65.3 by 1 inch, and see what we get. We have thus 64.3 inches as (say) an extreme upper limit for the group I907-II. Now, the sum for 1907-10 was known, viz. $54.5 ;$ and $64.3-54.5=9.8$ for March-August, I9II. The spring had $5 \cdot 2$ inches, so that we might look for a summer rainfall not over 4.5 inches. (The average is 6.7 inches.) The actual amount appears to have been 3.7 inches. The difference of the sums for 1904 and 1909 is $-\mathrm{I} \cdot 9$ inches; and the previous distribution of dots, indeed, points to a greater diminution than $\mathrm{r}$ inch. Alex. B. MacDowall.

\section{Limits of Explosibility in Gaseous Mixtures.}

In making experiments recently on the explosion of gases by means of an incandescent wire, I have obtained much wider limits of explosibility than those usually given. The following table shows the numbers obtained :-

\begin{tabular}{|c|c|c|c|c|c|c|}
\hline & & $\begin{array}{c}\text { Limits wit } \\
\text { plati }\end{array}$ & $\begin{array}{l}h \text { incan } \\
\text { umm wis } \\
\text { r cent. }\end{array}$ & escen & & $\begin{array}{l}\text { Limits } \\
\text { (Clowes) } \\
\text { Per cent. }\end{array}$ \\
\hline & & $\ldots \quad 2.5$ & to 24 & $\cdots$ & $\cdots$ & 5 to 13 \\
\hline & $\ldots$ & $\ldots$ & to 28 & $\ldots$ & $\ldots$ & 6 to 29 \\
\hline & $\ldots$ & $\ldots$ & to 75 & & & 5 to 72 \\
\hline
\end{tabular}

In each case the gas was mixed with air. The explosion was carried out in a glass tube of about to c.c. capacity NO. 2 I87, VOL. 87$]$ having a stop-cock at each end, and a mercury gauge of small bore attached to the middle of the tube. When the explosion occurs the mercury moves more or less sharply, according to the force of the explosion, but a distinct movement, apart from that due merely to the expansion caused by the heating of the wire, can be seen with the proportions of gases given above. The marsh gas was prepared from zinc methyl, as aluminium carbide, on treating with water, was found to give 33 per cent. hydrogen.

I am not clear as to why the limits should be wider than those usually obtained; possibly it is due to catalytic action of the platinum wire, or possibly the apparatus is more sensitive than that usually employed. The matter seems of interest in connection with colliery explosions. Using the same apparatus, I have obtained explosions with coal-dust and air, and with lycopodium powder and air, no other gas being present.

University College, Cardiff.

$$
\text { E. P. Perman. }
$$

\section{Working Hypotheses $v$. Collection of Bare Facts.}

Perhaps it is desirable to explain that my review of Prof. Schuster's book published in NATURE of September 21 was written and sent to you before Prof. H. H. Turner had delivered his address to the British Association as president of Section A. Consequently, nothing in my review is a reply to, or has any reference to, Prof. Turner's excellent address. It would be discourteous to criticise an important pronouncement of a leader in science in any back-handed way. My statement and his are probably not really in opposition, though they to some extent emphasise opposite types of investigating activity.

Oliver Longe.

\section{Use of Wind-furnaces in Smelting.}

IT may interest your correspondent, Mr. George Turner (p. $38 \mathrm{I}$ ), to be reminded that wind-furnaces (furnaces without any blast but that of the wind) were used, at all events for lead smelting, much less than goo years ago. Until some time in the seventeenth century the Derbyshire leadsmelters did not employ an artificial blast. They, like their predecessors in Roman times, built their furnaces on the tops of hills and facing the quarter of the prevalent winds. Dr. Percy in his "Metallurgy of Lead" gives extracts from Bishop Watson's "Chemical Essays" and from an earlier writer, Joshua Childrey, describing such windfurnaces.

Royal Society of Arts, W.C., September 24. H. T. WOOD

\section{Meteor-showers.}

Besides the ordinary display of Orionids that occurs near the middle of October, a considerable amount of meteoric activity may be looked for about the beginning of the month. Indeed, the intensity of the earlier meteorshowers promises to be considerably greater than that of any of the subsequent ones in October. The following are computed particulars of two important meteor-showers that become due before October 6 .

Epoch September 29, 3h. (G.M.T.), second order of magnitude. Principal maximum September $30,18 \mathrm{~h} .25 \mathrm{~m}$. Secondary maxima September 29, $16 \mathrm{~h} .$, and October 2, 16h. $25 \mathrm{~m}$.

Epoch October 5, 6h. 3om., third order of magnitude. Principal maximum October $3,22 \mathrm{~h}$. Iom. Secondary maxima October $2,2 \mathrm{~h} .45 \mathrm{~m}$., and October $4,1 \mathrm{rh}$.

After these there will be meteoric quiescence until October 12. John R. HEnRy.

2 Belgrave Villas, Rathmines, Dublin, September 26. 